Eixo Temático: - Formação Profissional do Biólogo

\title{
ET-02-001 \\ LICENCIADO EM BIOLOGIA: DESAFIOS, DIFICULDADES E DISCUSSÕES
}

Denise de Queiroga Nascimento ${ }^{1 *}$, Yorran Hardman Araujo Montenegro ${ }^{1}$, Tafarel Fernandes Tavares de Melo ${ }^{2}$

${ }^{1}$ Graduando em Ciências Biológicas, Universidade Estadual da Paraíba (UEPB).

${ }^{2}$ Mestre em Ensino de Ciências - Biologia (PPGECEM/UEPB). *E-mail: dennise.queiroga@gmail.com.

http://dx.doi.org/10.21472/congrebio2016.et-02-001

\section{RESUMO}

Este trabalho buscou por meio de uma revisão de literatura, identificar às principais dificuldades que são encontradas dentro dos cursos de preparação a docência, em especifico de Biologia. Os critérios para a seleção dos trabalhos foi à presença das palavras chaves tais como: "Formação do professor”, "Ensino de Biologia”, "Práticas pedagógicas”, “Atividade docente” e que fossem no formato de artigo encontrados no Google Acadêmico, seja publicado em revista ou anais de congresso. Foram analisados cinco trabalhos, com autores diferentes e em anos diferentes. $\mathrm{O}$ aspecto em comum presente em todas as pesquisas foi à desvinculação da teoria adquirida pelos alunos, futuros professores, no decorrer da sua formação no ensino superior e a prática, na qual estes se deparam com a realidade da profissão. Vários outros pontos foram argumentados pelos autores analisados que julgam de certa forma ser uma deficiência detectada nos cursos de licenciatura e precisam ser revistos pelos profissionais responsáveis pela preparação dos futuros docentes.

Palavras-chave: Formação do professor; Teoria/prática; Biologia.

\section{INTRODUÇÃO}

A produção de literatura direcionada à formação inicial e continuada do professor vem crescendo constantemente nas três ultimas décadas no Brasil e conta com um significativo acervo de teses e dissertações. Uma das produções que vem se multiplicando nos últimos anos são as pesquisa na área de Ensino de Biologia, na qual as investigações buscam caracterizar, sistematizar e realizar uma revisão crítica a cerca dos trabalhos acadêmicos que abordam, particularmente o ensino dessa área. Os principais eixos enfatizados nas publicações acadêmicas são principalmente voltadas a formação inicial do professor para o ensino de Ciências Naturais, propostas de reforma ns cursos de formação destes profissionais, propostas e/ou avaliações de programas de aperfeiçoamento, atualização, capacitação, treinamento ou especialização de professores, além da descrição e avaliação da prática pedagógica em processo de formação em serviço (SLONGO, 2004). Apesar de que a partir da decada de 90, houve uma intensiva produção de trabalhos que visaram à preocupação com o Ensino de Ciências Biólogicas (SLONGO, 2004), pesquisas voltadas para professores na área de Biologia ainda se encontra em minoria quando comparada a outras áreas como educação física e matemática, por exemplo, na qual são avaliados a mais tempo.

Em licenciaturas, como o caso aqui estudado, além dos domínios das competências específicas, conceitos, formulações e linguagem próprios de sua área, é necessário também compreender e administrar saberes pedagógicos, contextos educacionais, demandas sociais e didáticas, o currículo comum à Educação Básica e Superior (quando aplicável), a construção de método e os processos comuns à Educação. Os licenciandos em Ciências Biológicas se deparam 
já no início do currículo do Ensino Superior com componentes curriculares voltados ao Ensino de Biologia e obtém no máximo algumas experiências de "docência acadêmica" (SELLES; FERREIRA, 2009). Nesse contexto, os aspectos relativos ao tempo e os espaços para a produção de conhecimentos biólogicos chegam ao imaginário do futuro professor, gerando conflitos epistemológicos que marcam os processos de formação para a docência. Concordamos com a literatura em afirmar a importância de estudos com foco na análise curricular dos cursos de Ensino Superior, especialmente no que se refere aos contextos que levam à formação inicial destes professores (VIANA et al., 2012).

Para tanto, não se pode levar em consideração apenas as experiências pré-profissionais dos licenciandos, nem somente as experiências adquiridas em sua formação voltada para atuação do biólogo como suficientes para se tornar um "bom profissional". A docência, conforme apresentam Selles e Ferreira (2009), é uma "profissão aprendida" e por isso, tornar-se professor é um processo complexo, idiossincrático e multidimensional (FLORES, 2001) que implica em "aprender a ensinar".

Calderhead e Shorrock (1997), em discurso sobre a formação inicial, apontam uma tendência para simplificar o dilema entre a teoria (figurativamente própria à Academia) e prática (neste caso, relativa às instituções de Ensino Básico): O curso de licenciatura não está integrado ao verdadeiro exercício da profissão, sobretudo quando observada a carência relativa à abordagem interdisciplinar dos currículos e ao completo distanciamento entre universidade e a escola. ${ }^{1}$

Quando observado o ensino da biologia, depara-se com a problemática existente quanto ao aprendizado do estudante. Segundo as Leis de Diretrizes e Bases ( $2^{\circ}$, da LDB 9.394/96), o ensino deve acontecer de forma qualitativa, na qual o aluno desenvolva a autonomia para pensar e obtenha uma conduta crítica (SILVA et al., 2011).

No entanto, as dificuldades que regem os profissionais da educação podem ser resultado de um currículo que poderia ser trabalhado com maior ênfase na prática docentes e não se deter apenas no aprofundamento teórico de conceitos e formulações próprios ao Ensino Superior, algo que não substitui, mas, pelo contrário, confere maior integração com os estágios supervisionados.

Ao enxergar as diversas análises e concepções expostas pelos pesquisadores da área de ensino em Biologia, nota-se que há aspectos nesse processo de formação do professores que necessitam de ajustes e quando essas concepções apresentam fundamento, podem contribuir significativamente para a melhoria da educação, visto que se trata de preparação de docentes.

Portanto, é preciso verificar as principais concepções que as pesquisas nessa área vêm destacando nesses últimos anos para então detectar a contribuição que esta pode oferecer ao processo de formação de professores de Biologia.

\section{OBJETIVOS}

Elencar as principais concepções sobre o Ensino de Biologia apresentadas pela literatura da área, delineando um provável perfil comum dos licenciandos em Ciências Biológicas/Biologia.

\footnotetext{
${ }^{1}$ Apesar de encontrar algumas falhas no sistema de ensino nos cursos de licenciatura, algumas politicas governamentais e acadêmicas contribuem positivamente para a formação do professor. O Programa Institucional de Bolsas de Iniciação à Docência (Pibid), por exemplo, oferta bolsas de iniciação à docência aos alunos de cursos presenciais que se dediquem ao estágio nas escolas públicas e ao término do curso comprometam-se com o exercício do magistério na rede pública. Este programa objetiva vincular os futuros docentes a sala de aula de escolas públicas, incentivando dessa forma, a articulação entre as licenciaturas oferecidas no ensino superior e as escolas de sistemas estaduais e municipais.
} 


\section{METODOLOGIA}

Com a finalidade de elencar as concepções expressas em diferentes estudos da área de pesquisa relativa ao Ensino de Biologia, foi desenvolvida uma revisão bibliográfica sistemática. Esta é uma forma de pesquisa que utiliza a literatura como fontes de dados de um determinado tema, tornando-se útil para a integração de informações em um conjunto de estudos realizados separadamente e que podem apresentar resultados conflitantes elou coincidentes para o auxílio de investigações futuras.

Com o objetivo de delimitar o campo de pesquisa e o número de ocorrências, foi utilizada a base de dados do Google Acadêmico, escolha justificada pelo grande número de periódicos encontrados concernentes às áreas de Educação e Ensino de Biologia, optando pela busca através de conceitos ou palavras-chave, conforme apresenta a Tabela 1.

Foram critérios de inclusão trabalhos, escritos no modelo de artigo, no idioma português com delineamento experimental e resultados satisfatórios, publicados a partir de 2000. Os fatores de exclusão determinados foram para artigos publicados antes de 2000, escritos em uma língua estrangeira e que estivesse no modelo de dissertação, tese ou qualquer outro modelo que não seja classificado como artigo.

Tabela 1. Descrição dos cinco artigos escolhidos para análise por meio da busca das palavraschaves

\begin{tabular}{|c|c|c|c|c|c|}
\hline \multirow[b]{2}{*}{ Artigo } & \multirow[b]{2}{*}{ Autor/Ano } & \multicolumn{4}{|c|}{ Palavra-chaves } \\
\hline & & $\begin{array}{c}\text { Formação (ou } \\
\text { formador) do/de } \\
\text { professor }\end{array}$ & $\begin{array}{c}\text { Ensino de } \\
\text { Biologia }\end{array}$ & $\begin{array}{c}\text { Práticas } \\
\text { pedagógicas }\end{array}$ & $\begin{array}{c}\text { Atividade } \\
\text { docente }\end{array}$ \\
\hline $\begin{array}{l}\text { A formação de professores de } \\
\text { Biologia e a prática docente- } \\
\text { O ensino de evolução. }\end{array}$ & $\begin{array}{l}\text { Goedert et al. } \\
\text { (2003) }\end{array}$ & $\mathbf{X}$ & $\mathbf{X}$ & & \\
\hline $\begin{array}{l}\text { Formação dos professores de } \\
\text { ciências e Biologia: reflexões } \\
\text { sobre os conhecimentos } \\
\text { necessários a uma prática de } \\
\text { qualidade. }\end{array}$ & Malucelli (2007) & $\mathbf{X}$ & & & $\mathbf{X}$ \\
\hline $\begin{array}{l}\text { Algumas reflexões em torno } \\
\text { da formação inicial de } \\
\text { professores. }\end{array}$ & Flores (2010) & $\mathbf{X}$ & & & \\
\hline $\begin{array}{l}\text { A prática pedagógica e a } \\
\text { formação de professores de } \\
\text { Ciências e Biologia: Uma } \\
\text { experiência em construção. }\end{array}$ & $\begin{array}{l}\text { Oliveira et al. } \\
\text { (2007) }\end{array}$ & X & & X & \\
\hline $\begin{array}{l}\text { A pesquisa na formação } \\
\text { inicial de professores de } \\
\text { Biologia. }\end{array}$ & $\begin{array}{l}\text { Araújo e França } \\
\text { (2010) }\end{array}$ & $\mathbf{X}$ & & & \\
\hline
\end{tabular}




\section{RESULTADOS E DISCUSSÕES}

É preciso que os professores se atualizem para atender as novas demandas da escola, obtendo uma informação que seja baseada na prática e não somente na teoria. Segundo a pesquisa de Malucelli (2007), é preciso analisar as diferentes contribuições de professores que abordam a questão de "saber" e "saber fazer" para obter uma docência com qualidade. Ao analisar tais casos, pode-se pensar que os professores de Ciências não só carecem de uma formação profissional adequada, como também não estão cientes de suas insuficiências acadêmicas. Assim, o reflexo dessa formação é demonstrada na aprendizagem dos alunos. Trata-se então de orientar o trabalho de formação dos professores como uma pesquisa dirigida e de maneira efetiva gerar uma transformação em suas concepções iniciais. Em geral, é necessário conhecer a matéria a ser ensinada, adquirir conhecimentos teóricos sobre a aprendizagem, possuir capacidade critica fundamentada no ensino habitual, saber preparar e dirigir atividades dos alunos além de saber avaliar e utilizar a pesquisa e inovação.

Apesar da preocupação com o professor como um dos fatores essenciais para o processo de ensino/aprendizagem ser antiga e até recentemente os estudos concentravam-se nas características de um bom professor. Hoje, o debate é a cerca dos conhecimentos que os professores precisam adquirir. Para Malucelli (2007), essa ideia atual é uma superação de concepções essencialistas como, por exemplo, "professor é” ou "nasce” para isso, indicando mais uma ineficácia do que uma preparação de profissionais. Nenhum professor deve sentir-se suficiente no saber, mas o essencial é que possa ter um trabalho coletivo em todo o processo de ensino e aprendizagem indo desde a preparação das aulas até a avaliação. Esse processo leva a tarefa do docente como um trabalho coletivo de inovação, pesquisa e uma formação permanente. Somar a preparação cientifica e cursos gerais de educação para formar um professor parece ser sinônimo de fracasso, pois esse modelo somatório como base para a formação dos professores de Biologia, resulta em uma falta de interação entre os princípios teóricos estudados nos cursos de educação com a prática docente. Um programa eficaz para formar um professor é integrar os conteúdos disciplinares com a prática bem-sucedida. Assim, as reflexões feitas por Malucelli (2007) mostrou que o professor não se restringe somente a instituições educacionais, pois ele extrapola os muros da escola e interage com o mundo social, transmitindo não somente os conhecimentos, mas sendo mediador, legitimador e produtor de ideias e práticas sociais.

Na concepção de Goedert et al. (2003) em seu trabalho sobre a formação de professores de Biologia, os profissionais da educação identificam com facilidade suas limitações na sua prática docente. Muitas dessas, está relacionada a formação acadêmica, indo desde a condução de uma disciplina em especifico e a ausência de disciplinas optativas que propiciem um aprofundamento de conhecimento. Nesse trabalho, os autores relatam um aspecto bastante relevante no processo de formação do professor, ao mostrarem que para um bom preparo profissional dentro da sala de aula na qual vão exercer sua profissão é primordial que estes tenham recebido durante seu processo de formação uma boa aquisição de conhecimento sobre determinado assunto.

Nesse caso, o destaque é dado ao componente de evolução, matéria presente nos cursos de biologia. Quando, dentro do curso de educação, um determinado componente não é oferecido com excelência, seja por falta de profissionais, por questões de aplicação metodológica ineficaz ou outros motivos que não resultem em levar conhecimento ao futuro professor, uma hora ou outra isso irá requerer do novo docente um esforço ainda maior para compreender e repassar seus conhecimentos para a turma que lhe é entregue. Além de concordar no que diz respeito da ausência interativa da teoria com a prática no processo de formação docente destacada por Malucelli (2007), Goedert et al. (2003) mostra que a carência de materiais didáticos atualizados e carga horária de trabalho elevada interfere nos estudos profissionais para manter os professores atualizados e obter um bom preparo de aula já que na formação apresentaram um déficit de conhecimento em alguma área específica. Todos esses pontos demonstrados apontam para uma fragilidade nos cursos de formação do professor, uma vez que exista diferença entre 
aprender a teoria e aplicar de forma efetiva e adequada na realidade deparada em escolas de ensino médio e fundamental, por exemplo.

No trabalho de Flores (2010) sobre as reflexões a cerca da formação inicial de professores, enfatiza a importância de alunos, que serão professores, desenvolverem compreensões acerca do ensino e da aprendizagem investigando suas próprias práticas. Isso é um desafio, pois os professores não se sentem preparados para enfrentar a realidade da escola e da sala de aula. Isso confirma mais uma vez a relação teoria e prática abordada pelos autores anteriores. Na questão de estágios supervisionados, Flores em seus trabalhos, afirma que a qualidade na orientação juntamente com o apoio e trabalho de equipe na escola são determinantes para uma formação. O papel do professor, a natureza do currículo escolar, o estatuto e poder do professor estão vinculados aos cursos preparatórios a docência. Outro ponto relevante, segundo esse autor é a separação entre o mundo escolar e a universidade, gerando uma contradição na preparação dos professores. O processo de tornar-se professor fica descontinuo e fragmentado, onde na verdade se querem professores de qualidade nas escolas isso deve vir de um processo de preparação que precisam ser organizados em função da realidade, colocando de lado modelos tradicionais, escolarizados e baseados numa racionalidade técnica.

Como afirma Flores (2004) é fundamental promover espaços para os futuros professores para explicitar crenças e representações que eles trazem consigo para investigar e refletir sobre a prática docente e os propósitos que são subjacentes ao processo de tornar-se professor no sentido de construção pessoal do conhecimento sobre o ensino. Não basta somente enxergar falhas no curso de preparação do docente, mas este próprio reconhecer que a formação inicial é incompleta e se inscreve num processo formativo mais longo, integrado e holístico usando a lógica de desenvolvimento profissional e uma perspectiva de aprendizagem ao longo da vida.

Loughran (2009) afirma que a formação do professor deve ser coerente e holístico, requerendo um compromisso para investigar o ensino e ensinar a investigar. O ponto chave é encorajar os participantes dessa profissão a valorizar mais a natureza de seu trabalho. Assim, conduzirá a um melhor entendimento do ensino e do aprender a ensinar, construindo dessa forma um profissional mais fundamentado e reflexivo.

Ao analisar o artigo de Oliveira et al. (2007), referente à prática pedagógica e formação de professores em Ciências e Biologia, este declara que o papel do professor é muito diferente e por esse motivo a sua formação também deve sofrer transformações radicais. Essas transformações devem ser encontradas nas instituições superiores, amparadas por profissionais responsáveis pela preparação dos futuros professores. Além disso, a maior ênfase dada a essa pesquisa é sobre as práticas pedagógicas na qual devem favorecer um trabalho interdisciplinar, permitindo tanto que o futuro professor observe, conheça, interaja com o ambiente escolar, como também compreenda como se processa a interação entre os conteúdos das disciplinas de sua área em especifico para alunos de ensino fundamental e médio. A prática pedagógica possui 400 horas e devem ser bem distribuídas ao longo dos anos nos cursos de docência. Essa é um bom instrumento para a formação do professor.

Para Oliveira et al. (2007) o problema em geral enfrentado pelos futuros professores, é a tentativa de produzir um profissional que incorpore, o mais possível, traços ideais a partir de uma reflexão teórica sobre o assunto. Os pontos principais que resultam na formação do professor que se tem hoje é a memorização, distanciamento do cotidiano e do interesse do aluno bem como a pretensa neutralidade. Mais uma vez, tal artigo, concorda com a ausência interativa de universidade com as escolas, entre estudos teóricos e práticos.

Para mudar esse parâmetro seria necessário pensar em um modelo de formação docente que construa sua prática de forma autônoma, sem se desligar da realidade das escolas. A metodologia utilizada por Oliveira et al. (2007) é propor uma investigação da realidade dos professores na qual são inseridos, problematizem esses fatos, teorizem sobre este e criem uma proposta para solucionar o problema encontrado. Pretende-se que os alunos em fase de formação, percebam o ensino como fonte importante de pesquisa e acabando com a visão simplista da sala de aula e fazendo prevalecer à concepção que o ambiente escolar é um campo 
heterogêneo e frutífero para a reflexão do professor. A prática pedagógica, então, é uma boa ferramenta na qual o professor pode se aperfeiçoar e ativar o interesse dos seus alunos. $\mathrm{O}$ professor prepara e aplica atividades experimentais que de fato geram no aluno a curiosidade maior compreensão dos assuntos.

Procurando desenvolver essa ideia de prática pedagógica no ensino superior, Oliveira et al. (2007) buscou trabalhar com projetos nos quais os alunos escolhiam o tema e desenvolviam um projeto semelhante ao de iniciação científica. Primeiramente, foi oferecido disciplinas teóricas que dessem um respaldo aos participantes a fim de entenderem a dinâmica e os objetivos do curso. No terceiro ano do curso, há a prática de ensino, onde se encaixa os estágios supervisionados. O aluno submetido a essa fase, desenvolve uma pesquisa teórico-prática sobre um determinado assunto escolhido. Ao término dessas análises, chegou a conclusão que há constantemente uma ausência de relação direta entre teoria vista pelos alunos com as disciplinas pedagógicas junto a realidade com a qual estes passam no estágio supervisionado. As horas oferecidas para a prática pedagógica é uma possibilidade concreta de interação de teoria-prática ao longo do curso, pois se torna uma ação didática coerente com a concepção de professor que pretende-se formar. É notório, segundo este autor, que os alunos que participam das práticas pedagógicas durante os estágios, conseguem ser mais abertos quanto à escolha da escola que irão realizar o estágio, não se intimidam com escolas em periferia ou escolas conhecidas por apresentar turmas indisciplinadas, apresentam um conjunto de estratégias em sala, um número maior de atividades práticas na qual envolvem também problematização e contextualização, possuem melhor domínio de sala, além de manter a atenção dos alunos promovendo atividades que geram aprendizagem significativa.

O estudo qualitativo desenvolvido por Araújo e França (2010), intitulado como “A pesquisa na formação inicial de professores de Biologia” analisa a necessidade do professor ser um pesquisador também. Além de atuar na sala de aula para transmitir conhecimento o docente deve ser estimulado a desenvolver a pesquisa para que seja refletido dentro da sala de aula. Para estes autores, as disciplinas pedagógicas, geralmente ministradas por profissionais ligados a departamento ou centro de educação são vistas como disciplinas para o preparo do professor e as disciplinas especificas do curso são determinantes para os pesquisadores na qual gera uma distinção entre licenciados e bacharéis. Na verdade, é necessário que os futuros professores sejam críticos nas pesquisas produzidas no campo da educação. Assim, esses projetos de pesquisa, desmistifica a concepção de que a reflexão possa ser suficiente para promover uma formação eficaz. Só há sentido nas atividades de pesquisa na formação inicial de um licenciando quando esta produz melhorias na sua prática docente. Essa participação da pesquisa leva a possibilidade de lidar diretamente com o conhecimento cientifico e desenvolver dessa forma atitudes e habilidades de um pesquisador, como a curiosidade, observação e senso critico, atividades estas essenciais para um professor. Pesquisa é a palavra-chave quando o ensino e currículo são tratados de um modo crítico e estratégico e que a ampliação desse movimento na formação dos professores pode levar pessoas de diferentes partes do mundo a compartilhar experiências e lutar por melhores condições de trabalho e qualificação profissional. Em sua pesquisa qualitativa desenvolvida com alunos concluintes de uma Universidade Federal de Recife, Araújo e França (2010) observaram que os bolsistas do Programa Institucional de Iniciação à Docência (Pibid) são poucos no universo acadêmico e a elaboração de monografias é outras formas de pesquisa são os mais responsáveis pelo acesso desses estudantes no campo da pesquisa. Os alunos que afirmaram não estar preparados para a pesquisa atribuem o fato da ausência no incentivo dos professores e pouco estimulo encontrado em demais componentes curriculares. Os licenciados que afirmaram ser preparados para a pesquisa afirma que isto é algo promovido por uma minoria de docentes, limitado aqueles que orientam Pibid ou monografias. Apesar disso, foi perceptível nessas analises que os alunos desejam ser preparados para a pesquisa e dessa forma é necessário uma análise urgente de professores para a educação básica fundamentada na prática da pesquisa. Além disso, os futuros professores se deparam com um desestimulo de professores veteranos frente à realidade inserida e mais uma vez enxerga-se a necessidade do estágio supervisionado para que estes profissionais entrem em contato com os 
fatos e possa promover a realização de pesquisas e reflexão sobre a prática, contribuindo para a formação de professores pesquisadores que podem gerar inovações no âmbito escolar.

Mediante todas essas verificações literárias observa-se que todos os autores destacam o que todas as demais literaturas afirmam a cerca da formação do educador, em especifico de Biologia. Os cursos preparatórios de professores carecem de uma mudança no aspecto de ensino e a levada dessa teoria a prática no seu ambiente de trabalho que é a sala de aula. Para Viana et al. (2012) de modo geral, a visão sobre a formação de professores poderia ser estendida como um processo de construção de saberes docentes que ocorre em diversos espaços educativos. A docência é uma "profissão aprendida".

\section{CONCLUSÕES}

Nota-se que é preciso um ajuste nos cursos de licenciatura em específico de Biologia quanto à preparação de docentes. Todos os autores analisados apontaram pontos deficientes que de forma direta pode influenciar no êxito de um aluno que decide seguir a carreira de professor. Um ponto em comum entre eles foi a falta de interação entre a teoria mostrada aos alunos dentro da sala de aula de ensino superior com a prática que estes terão em um ambiente escolar. Além dessa ideia em comum, cada pesquisa destacou um aspecto diferente que vem também apresentando falhas e se consertadas podem contribuir significativamente na formação do docente. As maiores necessidades destacadas foi o embasamento melhor de disciplinas em áreas especificas dentro do ensino superior, visto que os professores recém-formados irão ensina-as na escola, reflexão e investigação no preparo e exercício da função docente, além da necessidade de investir nas práticas pedagógicas e não ter o foco apenas em componentes educacionais, mas que os professores também sejam estimulados a aliar a licenciatura à pesquisa. Portanto, todos esses pontos relevantes são importantes para formar um excelente professor na qual as escolas almejam, e obtendo uma preparação adequada, os futuros professores estarão aptos a encarar a realidade que o ambiente escolar apresenta.

\section{REFERÊNCIAS}

ARAÚJO, M. L. F; FRANÇA, T. L. A pesquisa na formação inicial de professores de Biologia. Revista Polyphonía, v. 21, n. 1, p. 201-215, 2010. http://dx.doi.org/10.5216/rp.v21i1.16300

CALDERHEAD, J; SHORROCK, S. Understanding teacher education. Case studies in the professional development of beginning teachers. London: Falmer Press, 1997.

FLORES, M. A. Algumas reflexões em torno da formação inicial de professores. Educação, v. 33, n. 3, p. 182-188, 2010.

FLORES, M. A. Person and context in becoming a new teacher. Journal of Education for Teaching, v. 27, n. 2, p. 135-148, 2001. http://dx.doi.org/10.1080/02607470120067882

GOEDERT, L; DELIZOICOV, N. C; ROSA, V. L. A formação de professores de Biologia e a prática docente: o ensino de evolução. Atas do IV Encontro Nacional de Pesquisa em Educação em Ciências (ENPEC), Bauru-SP, ABRAPEC, 2003.

MALUCELLI, V. M. B. Formação dos professores de Ciências e Biologia: reflexões sobre os conhecimentos necessários a uma prática de qualidade. Estud. Biol, v. 29, n. 66, p. 113-116, 2007. <http://www2.pucpr.br/reol/index.php/ BS?dd1=1909\&dd99=pdf>. Acesso em: 12 abr. 2016. 
OLIVEIRA, V. D. R. B.; GARAVELLO, C. R. G.; MIGUEL, M. M. B.; NASCIMENTO, E. G. A prática pedagógica e a formação de professores de Ciências e Biologia: uma experiência em construção. Anais do VI Encontro Nacional de Pesquisa em Educação em Ciências, Rio de Janeiro, 2007. Disponível em: <http://www.nutes.ufrj.br/abrapec/vienpec/CR2/p675.pdf>. Acesso em: 12 abr. 2016.

SELLES, S. E.; FERREIRA, M. S. Saberes docentes e disciplinas escolares na formação de professores em Ciências e Biologia. Ensino de Biologia: Histórias, saberes e práticas formativas. Uberlândia: EDUFU, 2009. p. 49-69.

SLONGO, I. I. P. A produção acadêmica em ensino de Biologia: um estudo a partir de teses e dissertações. Florianópolis: Universidade Federal de Santa Catarina, 2004. (Tese de doutorado). Disponível em: <https://repositorio.ufsc.br/bitstream/handle/123456789/88012/205538.pdf>. Acesso em: 12 abr. 2016.

VIANA, G. M.; MUNFORD, D.; FERREIRA, M. S.; MORO, L. Relações entre teoria e prática na formação de professores: investigando práticas sociais em disciplina acadêmica de um curso nas Ciências Biológicas. Educação em Revista, v. 28, n. 4, p. 17-49, 2012. http://dx.doi.org/10.1590/S0102-46982012000400002 